\title{
EDITORIAL
}

\section{Population Growth - Fertility, Health, and Poverty}

\author{
NS. Deodhar
}

\section{Introduction}

India was the first country in the world to adopt family planning as an official program in an effort to check rapid growth of its population which was causing a major constraint in its endeavor for socioeconomic development and a welfare society. During the past 54 years, the family planning program in India has been modified from time to time, both in terms of its approach and its content. Even the objective was broadened from family planning to family welfare. In spite of the high priority, huge infrastructure and funds provided, the outcome is not satisfactory. Recently, the total population of India has passed the billion mark. Last year the Government of India issued the National Population Policy, 2000 statement. A National Commission for Population, with the Prime Minister of India as its Chairman, has also been established. The Commission will oversee and review the implementation of the Population Policy (Department of Family Welfare, 2000). In the following sections I focus on the issue of population growth and its effects as a bio-social crux issue.

\section{Bio-social phenomenon}

Growth of a human population is a bio-social phenomenon. The inherent biological capacity to reproduce helps continuation of a family/community, a process similar to that of other forms of life for the survival of the species. Biologically, growth rate is a function of the fertility of a population, its level is determined by capacity of the population to survive. Human fertility level is also determined socially both by the extent and the degree of welfare of the families belonging to a particular socioeconomic group of a society. Table 1 depicts the result of the World Bank sponsored 1992-93 sample survey covering over 500,000 population in India. The variations in the selected health, nutrition, and population indicators are significantly higher between the rich and the poor (World Bank, 2000). Infant mortality rate is one and a half times higher among the poor than among the rich. The under-five mortality rate among the poor was 280 percent the same rate among the rich. While the Total Fertility Rate was nearly two times higher in the poor than that of the rich. The differences in coverage in high priority preventive programs such as immunization also indicates the seriousness of the situation and limitations of the current strategies.

Table 1: India 1992-93: Health, Nutrition, Population, and Poverty in Total Population (Laurence, 2000) $($ Sample size $=500,755)$

Indicator
IMR/ 1000 births
USMR/1000 births
Total Fertility Rate
Age-specific fertility rate/ 1000 women
Immunization coverage
- For all vaccines ( $\%)$
- Not immunized at all (\%)
Delivery attended by a traned person $(\%)$
Use of contraceptives by married women (\%)

\begin{tabular}{|c|c|c|}
\hline \multicolumn{3}{|c|}{ Socioeconomic status } \\
\hline Poorest & Richest & Average \\
\hline 109.2 & 44.0 & 86.3 \\
\hline 154.7 & 54.3 & 118.8 \\
\hline 4.1 & 2.1 & 3.4 \\
\hline 135 & 45 & 116 \\
\hline 17.1 & 65.0 & 35.4 \\
\hline 48.4 & 7.9 & 30.0 \\
\hline 11.9 & 78.7 & 34.3 \\
\hline 24.9 & 50.6 & 36.5 \\
\hline
\end{tabular}

These data corroborate the global bio-social phenomenon that rich people tend to have smaller families and the 
poor generally have larger families. Epidemiologically, this data establishes a cause-effect relation between socioeconomic status of people and their fertility. Thus, the variance or differences in fertility rates are not because all the rich have adopted the small family norm and have deliberately limited their family size. The variance in fertility rates is a natural effect of better survival and better quality of life among the rich. Likewise, the poor have larger family because of high fertility - a biological effect of poverty leading to lower potential for survival. The popular notion that the poor deliberately produce more children to offset high child mortality, is not correct. The fertility among elephant's is the lowest, while the rats breed abundantly. In the light of this perspective, what should be the basic strategy to arrest rapid growth of population?

\section{Suggested strategy}

There seems to be no alternative to a totally integrated and comprehensive strategy with effective decentralization and active participation of the people. Hart's invert care law (Laurence, 2000) i.e., those most in need are the least likely to receive the care they need, has to be overthrown and reversed. The following are the recommendations for consideration -

- Basic strategy should be alleviation of poverty.

- Concentrate on the welfare of families below poverty-line and give highest priority to places where the problem is the highest, vie., Uttar Pradesh, Bihar, Madhya Pradesh, and Rajasthan -- the Northern States. This will have a significant and lasting effect in lowering fertility.

- Poverty is essentially a long-term or chronic deprivation syndrome. Poverty is both the effect \& cause of several factors. Poverty is not just about socioeconomic hardship and social injustice. In order to have the desired effect on reduction of poverty, focused efforts of the Government, corporate, private, and voluntary sectors will be necessary. All departments and agencies of the Governments and the Panchayat Raj Institutions (PRIs or local self government) will have to be activated to do their lot effectively and in a sustainable way.

- Winding down the Department of Family Welfare at the Central and State levels. In practice, this would mean merging this Department with the Department of Health (to be rightly called the Public Health Department). This will considerably and surely help to ensure that the responsibility for controlling population by reduction in fertility becomes universal and taken over by every concerned Government department, agency, and sector. The role of every Ministry and Department of the Government should be identified and the specific Ministry/Department should be made accountable for their contribution towards lowering fertility and controlling population growth. Special efforts are necessary to ensure that various programs and interventions reach all the families below the poverty line, irrespective of their location, social and occupational status, etc.

It will be the function of the National Commission for Population to monitor, direct, and guide the State Governments in the effective implementation of the various programs and specific interventions for fertility control and poverty alleviation. States should be encouraged to set-up State Commission for Population. Statewise subcommittees should be nominated for the supportive and monitoring operations of the National Commission.

Specific roles and accountability of selected Ministries and Departments : At the Central, State, and local-self Governments, a joint exercise is necessary, separately with each Ministry and department, to define the specific roles vis-a-vis poverty alleviation and fertility control, and reach agreement on decentralization, devolution of power and authority, adequate resource allocation, effective implementation, review, and reaching time-bound objectives. The following are some illustrations -

\section{Public Health Department}

1. To ensure that the full package of primary health care is provided to all the families below the povertyline, irrespective of their location, social and occupational status, etc.

2. To strengthen all dimensions of public health services in general 
3. To promote and provide counseling, consultation, and contraceptive services, especially to all the families below the poverty-line.

4. To take steps, effectively and urgently, to ensure that all unmet needs are met.

\section{Education Department}

1. To adopt a time-bound program to provide primary education to all male and female children of all the families below the poverty-line, irrespective of their location, social and occupational status, etc.

2. To plan and implement schemes to encourage the children of families below the poverty-line to continue education until class ten initially and later until class twelve.

3. Special schemes should be provided for various kinds of vocational training having income-generating potential. Children from the families below the poverty-line, especially those whose performance in the schools is poor or those with necessary aptitude, should be given the highest priority. Free of cost placement outside their place of residence should be provided, if local facility is poor or not available.

\section{Department of Rural Development}

1. To ensure gainful employment and/or adequate income generation to all the families below the povertyline. Income should be adequate and sustained at appropriate level to be determined annually.

2. To provide basic healthy environment, especially safe drinking water and disposal of excreta, to all the families below the poverty-line.

\section{Food Department}

1. To ensure nutrition security through the public distribution system and/or other manner, to all the families below the poverty-line

\section{Department of Works and Housing}

1. To provide healthy housing and to ensure environmental hygiene to the poor, especially those families below the poverty-line.

\section{General Administration and Revenue Departments}

1. To ensure that social injustice and discrimination are undone, especially in respect of the poor

2. To restore the rights and property unlawfully takers away from the families below the poverty-line

3. To discourage crime and antisocial activities by providing acceptable alternatives.

\section{Conclusion}

It is necessary to reiterate that there seems to be no alternative to a totally integrated and comprehensive strategy with effective decentralization and active participation of the people. Health reforms should focus on primary health care, social justice, integration, and the have-nots. The disproportionate allocation of Government funds and other resources to the secondary and tertiary health care, commercialization, and mystification ought to be avoided.

\section{References}

Department of Family Welfare. 2000. National Population Policy. New Delhi: Department of Family Welfare, Ministry of Health and Family Welfare, Government of India 
World Bank. 2000. Country Reports on Health, Nutrition, Population Status and Service Use among Poor and Rich, India, HNP. May. (Also on World Bank's Health and Poverty Website :

www.worldbank.org/poverty/health/index.htm)

Laurence, M. A new primary care service delivery model. Melbourne: Global Health Reform, Australian International Health Institute, University of Melbourne.1: 2.

(This editorial reflects solely the personal views of the authors, and not of the Journal and persons and institutions associated with it.) 